\title{
Food Waste: An Exploratory Study of the Stakeholders' Perceptions
}

\author{
Paul Leung (Corresponding Author) \\ The Vocational Training Council (VTC) \\ Hong Kong \\ E-mail:paulkh@vtc.edu.hk \\ $\&$ \\ Jamie Lo \\ College of Professional and Continuing Education (CPCE) \\ The Hong Kong Polytechnic University \\ E-mail: jamie.lo@cpce-polyu.edu.hk
}

\begin{abstract}
The abstract should be 50-80 words (full paper: 80-120 words). Outline the aim of the study with a brief background to explain why it was needed, what was done, and the main findings. Avoid quotes and extensive references. Food waste has created pressure to the close-to-capacity landfills and created hygienic concerns. The current measures, both upstream reductions and downstream alternate utilizations together, faced with delimitations. This qualitative study aimed at revealing the perceptions and acceptance of the trade and dinners over food wastage control by interviewing key informants and identifying more effective measures. Findings indicated that there was critical misconception of waste control. Besides, cultural issues and custom norms have to be included in the planning and implementation of related strategies.
\end{abstract}

\section{Keywords:}

Food Wastages, Rectifying Measure, and Stakeholder Perceptions and Acceptance

\section{Introduction}

Greta Thunberg, the 16-year-old Swedish activist, was selected by the TIME magazine as the Person of the Year 2019. "Meaningful change rarely happens without the galvanizing force of influential individuals..." (TIME 2019) and Grata demands action to rectify the situation. According to the TIME magazine, corporate awareness and commitments to sustainable growth are on the rise but more need to be done.

A net carbon footprint of zero by 2050 is, however, perhaps too far off and linent a target. An early projection in 2000 estimated the potential climatic consequences of the increase of emulation of atmospheric greenhouse gas (GHG) concentration and sulfate aerosol loading for the years 1900 to 2100 based on five simulations with the CCCma coupled climate model. Results wave an alarm of a global mean temperatures increment of $1.7^{\circ} \mathrm{C}$ by 2050 and a further $2.7^{\circ} \mathrm{C}$ by 2100 . As a result, decreases in soil moisture, snow cover and sea-ice retreat are expected to sustain, which created further climate issues such as the sea-level changes. (G. J. Boer, G. Flato and D. Ramsden, 2000).

Although Boer et al (2000) contented that there are a list of factors, which would affect the actual temperature changes, the latest development actually gave a warning signal. According to the State of the Climate May 2019 report, 2015 has the warmest March-May period for both the global land and ocean surfaces in the 140 -year record at $0.96^{\circ} \mathrm{C}$ above the 20th century average and $0.15^{\circ} \mathrm{C}\left(0.27^{\circ} \mathrm{F}\right)$ less than the record set in $2016\left(+1.11^{\circ} \mathrm{C} /+2.00^{\circ} \mathrm{F}\right)($ State of the Climate 2019). The State of the Climate 2019 May Report, available on: above the 20th century average and $0.15^{\circ} \mathrm{C}\left(0.27^{\circ} \mathrm{F}\right)$ less than the record set in $2016\left(+1.11^{\circ} \mathrm{C} /+2.00^{\circ} \mathrm{F}\right)$. The global land-only temperature $\left(+1.90^{\circ} \mathrm{C} /+3.42^{\circ} \mathrm{F}\right)$ and the global ocean-only temperature $\left(+0.74^{\circ} \mathrm{C} / 1.33^{\circ} \mathrm{F}\right)$ above average are both the second highest in the 140 -year record, behind the record of 2016. For the same period, Hong Kong was $23.7^{\circ} \mathrm{C}\left(74.7^{\circ} \mathrm{F}\right)$ or $1.2^{\circ} \mathrm{C}\left(2.2^{\circ} \mathrm{F}\right)$ above average. This was one of Hong Kong's five highest spring temperatures on record. The results indicated that the actual situation is even worse than the prior projection in 2000 . 


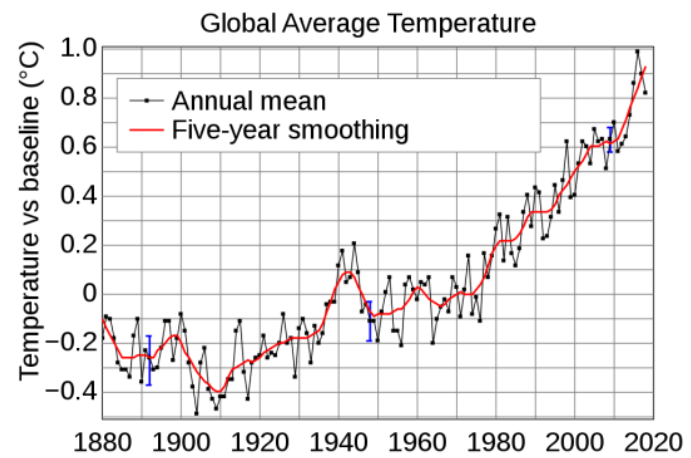

Source: NASA Goddard Institute for Space Studies

Global warming is only the first wave of impacts, which will follow by more frequent droughts, stronger storms and heavier rainfall. While the elongated heat waves have already caused many human lives, the impacts are expected to escalate. Actions to prevent if not turn around the situation have to be implemented with no further delates.

This study is part of a bigger project on the research for reducing food waste for the reduction of emulation of $\mathrm{CO} 2$. The overarching project will look into practical solutions to reduce and reuse food waste through various means including upcycling and community foodbanks. This study attempts to review the current practices, if any, amongst restaurateurs, investigate the barriers that they have encounters, and the perceptions about food waste reduction measures among restaurant management and customers.

\section{Food Waste}

To justify the importance of studying this modern social phenomenon, it would be its seriousness and intensity. The following factsheet was used as stimulus to facilitate the discussion with the key informants.

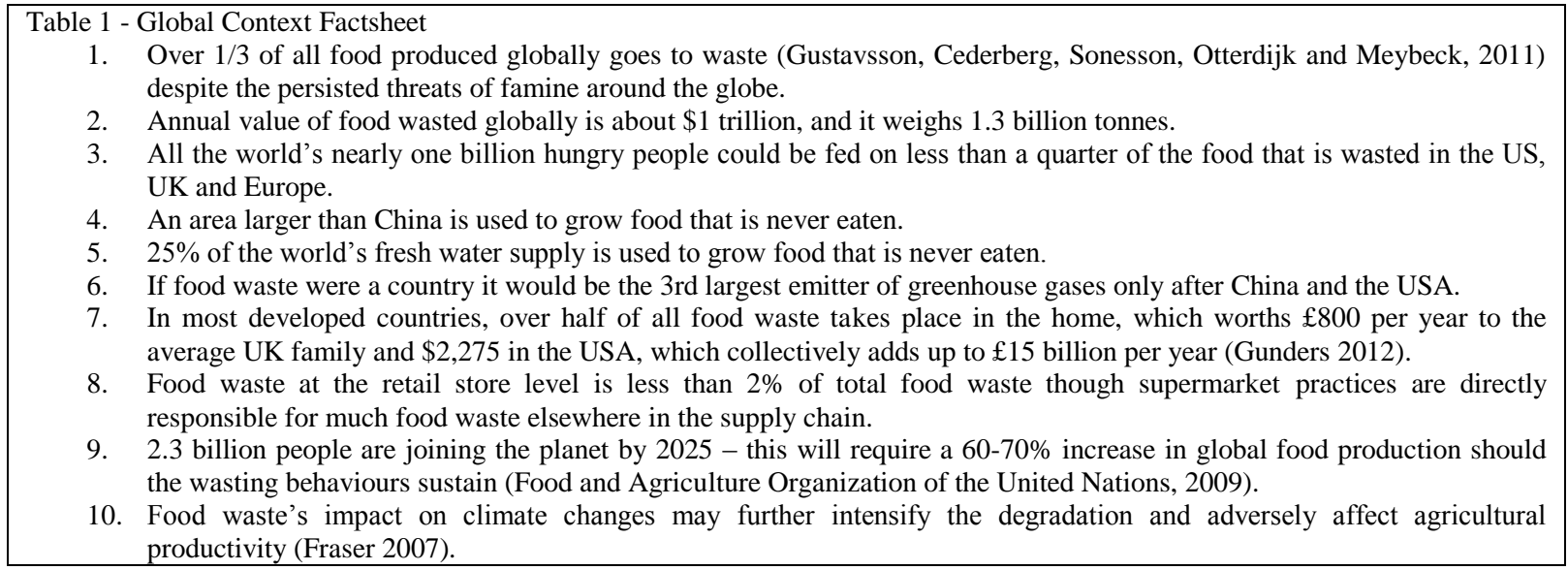

This study focus on the investigation of human / operational issues pertaining to the mitigation of the problem of food wastages. The researchers have a strong proposition that by reviewing the stakeholders' perceptions about foot waste control, some critical barriers can be identified for actions.

The researchers propelled a 5-R approach to the reduction of food wastages, which include Recognize, Rectify (Remedy), Reverse, Reduce and Reutilize. In reutilization, there are two major paths, viz., recycling and upcycling. To differentiate it from the prior model such as the one by Paragyopoulou et al (2014), the new model included two new emphasis and they are recognition and upcycling.

\section{Literature Review}

2.1. Food Waste The social issue of food waste is serious both in terms of its scale and impacts to the global village. Parfitt et al (2010) highlighted the scale and scope of the problem especially when the world population will hit 9 billion in 2050. They particularly emphasized the criticality of affecting behavioural changes for the reducing food 
waste. It may be worthwhile to notice that the current world population is already 7.8 billion in early 2020 and the United Nations has revised the projection to be 9.8 billion by 2050 and 11.2 billion in 2100 . Population has increased more than 4-fold during the $20^{\text {th }}$ century. With so many more people to feed, the output of food remained somewhat constant and the phenomenon of food waste has been escalating.

While the prevalence of undernourishment has improved from what was $13.1 \%$ in 2007 to $10.9 \%$ in 2017 , the prevalence of severe food insecurity raised from what was $8.9 \%$ to $10.2 \%$.

\subsection{Food Waste Management}

Food waste has very significant impacts to the environment, the society and economy concerned. Therefore, appropriate rectifying strategies are credential to the sustainability of the global village (see UNEP, 2011 and UNHSP, 2010). Papargyropoulou et al (2014) proposed a conceptual explanation to and a hierarchical approach to manage food waste (see Figure 1 and 2).

Figure 1 roughly estimated the food loss by activities in the food supply chain. The chain of losses, however, does not ended with the net availability for consumption. In fact, a lot more wastages happen after that.

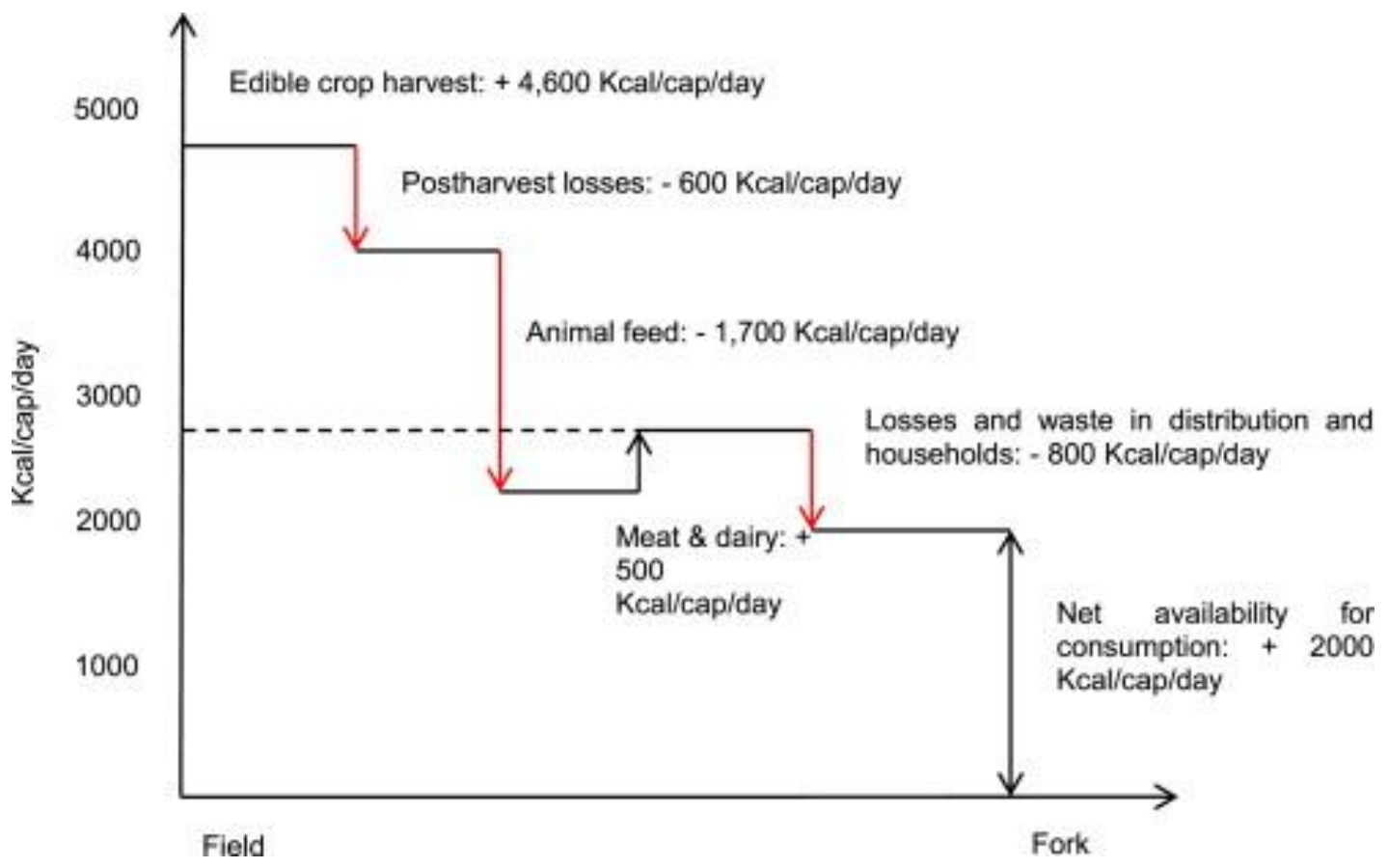

Source: Papargyropoulou et al (2014)

Figure 2: The Wastage Hierarchy 


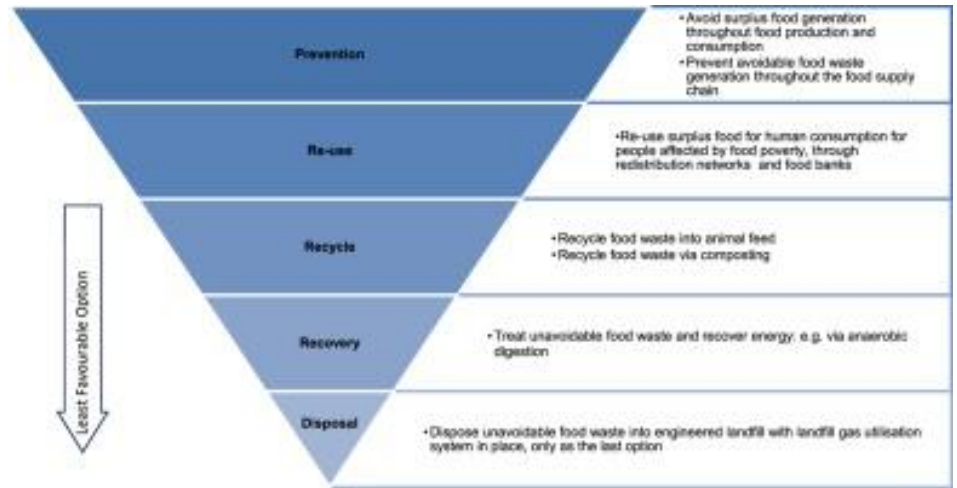

Source: Papargyropoulou et al (2014)

Paparguropouluo et al (2014) continued with the development of hierarchy approach to the management of food waste (see Figure 2). They suggested a five level approach, which included preventation, prepare for re-use, recycle, recovery and disposal. There are two insights that are of particular importance. First, their emphasis that prevention is the most important and starting step for waste control. Second, re-use and recycle should be planned in advance. The model, however, does not address the issues in related to human-driven causes to food waste. That means, there are food waste that is due to the cognitive choices of the industry and consumers, which will not avoided by their preventive measures. The researchers suspected that education and customization of environmental sensitive and responsible consumer behaviours might be as important.

Tukker (2010) also argued that food waste management is an issue within the field of sustainable consumption and production. The emphasis on any one of the two parts would be partial and might not be able to address the issue in a realistic and effective manner.

\subsection{Food Waste Conceptualization}

\subsubsection{Causes of food waste}

The Swedish Institute for Food and Biotechnology conducts two studies on food wastages and compared the different causes of developed and less developed countries contributing to the escalating social phenomenon of food waste. The studies covered seven (7) regions and different sectors on the supply chain. The study sub-classified foods into eight (8) categories and discovered that the lowest level of wastage was 'milk' in India (11\%) and the highest being Roots and tubers in the North America and Oceanic region (60\%) (Gustavsson, Cederberg and Sonesson, 2011).

The researchers suggested that the holistic view of food waste should include food waste along the supply-chain from pre-production, during production and post-product; waste out of malpractices and pragmatic need; and wastes in related to consumers behaviours. While waste along the supply line has received most of the attention in researches, the other two dimension deem to deserve more efforts and attentions.

\subsubsection{Causes of failure of anti-food waste programs}

While there are many studies on the causes and situation of food waste, studies on the causes for the failure of anti-food waste programs are scant. This indicated the importance of studies to provide information for the design and implementation of anti-waste programs. Dai et al (2016) conducted an interesting and meaningful study on domestic waste sorting, the failure of information-based programs and the success of personal interaction. Although it is not directly related to the main scope of this study, it clearly indicated the importance of human factor in the education and behaviours changing initiatives.

\subsubsection{Recycling and Upcycling}

Food waste upcycling or upcycled food is a relatively new term and approach to handle leftovers from processing and inject new value to a new product for consumption (see Waste360.com). The beauty of this new direction is the valueadding approach to waste control. According to Devenyns (2019), food waste is a sizable business with an estimated worth of $\$ 46.7$ billion in 2019 . His estimate, however, was only based on the rejected food materials. If the natural waste, such as coffee waste after extraction, could be utilized, the economic value would be further escalated while pressure on landfill relieved. 


\section{Methodology}

\subsection{Measurement}

The methodological design and the selection of methods being used reflect the objectives of the study to know the what, how and why the traditional food wastage controls have not been effective. The study aim to explore and understand the phenomena, mentalities, behaviours and motives behind behaviours. It adopted a qualitative approach that is better fitting into the quest for describing, interpreting and gaining in-depth insights into the respondents' views, level of acceptance and perceived barriers to measures to reduce food waste.

In-depth interviews were conducted with a selection of key informants, who included dinners with different demographic backgrounds, restaurateurs, hoteliers and waste-control related calibres. The interviews were conducted in Hong Kong and a total 50 interviewees were invited for the interview and 27 were successfully conducted. The data collection process ended before the planned deadline as the findings appeared to be saturated.

A list of open-ended popping questions and follow-up inquires were prepared for the investigation. Informants were presented with a factsheet to facilitate their participation (please see Table 1 for details). In order to enhance the depth of the findings and to reach correct response through consensus, Delphi technique has been capitalized with the interviews of the informants.

\section{Results}

\subsection{Profile of respondents}

As the researchers expected, the respondents of different segments enormously agreed with the needs for environmental conservation. Some, however, indicated their reservations on the impacts of anti-food waste measures might lead to cost inflation and affect the quality of the served dishes. After showing the factsheet on the current magnitude of food waste and the problems including overfull landfills, climate changes and famine, all respondents reached the consent that there should be measures to reduce food waste. With this, they were asked to suggest their perceived causes to food wastes, possible alternative measures, perceived barriers to the implementations, rationales behind the resistance and resolutions, if any.

The perceived causes behind food waste can be sub-categorized into three major areas, viz., supply-chain production reasons, cultural norms and consumer preferences, and management misconceptions. Although supply chain and production reasons have been acknowledged in past reaches, new dimensions have been identified. The study also identified the other two new dimensions, which is worthwhile to notice, especially among the Asian markets.

Respondents contented that dinning out as a social occasion has an impact on the ordered quantity and quality. In other words, consumers would tend to order more than they needed, and demand for higher perceived quality including garnishing. These tendency was argued to be particular obvious among Asians. For the Chinese, as an example, it is a basic courtesy and ritual to offer more than enough food and drinks to their guests. On the other hand, a guest should never finish the dish. The result are leftovers and larger quantities of waste in production.

Respondents expressed their views on served portions. They generally agreed that consumers would prefer bigger portion than they can consume for value of their spending. Restauranteurs also indicated the same concern in their portion design. An effective and flexible mechanism for portioning the dishes might rectify the situation.

Restauranteur respondents also shared a common view on the side dishes and garnishing. They perceived these as essential part of their dishes and indications of their quality. Taking away garnishing would have detrimental impact on the perceived quality of the dishes and the catering outlet. Dinners, however, have a slightly different view. When they were asked about whether they would expect garnishing in a fine dining restaurant, the responses were affirmative. Some even said that it is essential. However, when they were asked about whether they would accept smaller portions, no or limited side dishes, and no garnishing for environmental protective purposes, they seem to be very positive. In other words, if they menu design and the dining outlet can communicate with the dinners on these aspects, dinners can accept and even give credits to the arrangement.

\section{Discussion and Conclusion}

\subsection{Discussion}


While the researchers have the preposition that there will be fundamental differences between the catering operators and the customers, the initial findings indicated that they have more similarity in practice. They concerted with the needs for reducing food waste, they agreed that waste is primary a consumer-led phenomenon. While the logistic, supply-chain and production process could be improved to reduce wastage, the most important aspects were largely related to the dinners' behaviours. Cited below are the suggestions on the possible measures to reduce food wastes.

The interview embarks on generic perceptions related to environmental preservations. All key informants are positive to the environmental protection through alternating consumptions.

In other words, consumers are willing to change their buying and consumption behaviour in view of environmental preservation. All informants agreed that it is both the consumers' and the businesses' responsibility to preserve the environment even if there would be a cost to pay.

Respondents, being restaurant management / owners, however, expressed their concern about the perceived quality of their offerings and the satisfaction of their customers. Given the difficult operational environment and severe market competitions, the ruling principle has to be the acceptance and level of appreciation among customers. In other words, restauranteurs are likely to be relatively passive and react to their market's preferences and acceptance. They, in general, were not prepared to take the lead and to influence their customers' behavirous. In this regards, it seems to be sensible for NGOs or a government bureau to promote responsible consumptions, which in turn trigger changes among the restauranteurs.

When asked about whether they are willing to foregone signature dishes in view of environmental protection, the responses seem to be diversified. One of the chef responded that catering outlets have to advance in their corporate citizenship and operate in more ethical ways. He mentioned about the use of induction cooking, which was by and large not accepted amongst traditional Chinese catering outlets in the old days, is gaining more and more acceptance. Likewise, shark fins as a must ingredient in Chinese banquets is losing its prominence for animal rights concerns. As a responsible chef, as he contented, one should look for alternatives to rectify the drawbacks of environmental measures and to ensure a win-win outcome.

A restaurant owner, however, indicated his concerns over survival and use agreed by other respondents. Unless the clients can appreciate the environmental practices, customers will vote with their consumption and unwelcomed or unflavoured drives could be detrimental to business.

Consumers, on the other hand, seem to be more receptive to protective measures. They commented that they will be willing to sacrifice savour and enjoyment for environmental protection. For example, they will be willing to give up eating shark fins and endangered species. They, however, also contented that their tolerance would have a limit. Satisfaction is still important.

The discussions then follow onto the topic of food waste. All key informants are positive to the environmental protection through the reduction of food wastes. Although they seems to have relatively limited awareness of the scale and impacts of food wastages, their general attitude towards measures to reduce wastages even at the expenses of their enjoyment and/or presentation quality remain supportive.

\subsection{Conclusion}

As a conclusion to this initial round of the study, findings indicated the essentiality of education and communications for the effective implementation of environmental initiatives. Even if the propelled initiatives appears to be hazardfree, no cost implications, effective in achieving the observable results and supported by government policies, stakeholders might have different concerns and / or reservations that lead to their uncooperativeness and subsequently the failure of such programs. Some of these resistances might be induced by lack of knowledge and information, mispresentation, wrong information or perceptions, emotional barriers, political affiliations, and incompatibility to their culture norm and customs.

Especially in this era of social media, influences came from all sorts of sources, which go beyond the traditional peer influence. Messages coming from unknown sources with claims that cannot be verify are still accepted by many people. Perhaps under the influences of negativity, many people will not question about the trustworthiness of these unidentified information. On the contrary, messages from official bodies, the government in particular, would receive a lot of criticism and doubts. Government will be allegated for hidden agenda, trade bodies will be accursed for their conflict of interest, NGOs will be criticized for their lack of professional knowledge, and even international organizations might have difficulties in building credibility. 


\subsection{Limitations of this study}

The methodological design of the study reflects the exploratory nature of the study. The findings and discussions are restricted in terms of their representativeness. The selection of Hong Kong Chinese as respondents is partly due to the unique dinning culture of the subject group and for convenience purpose. Once again, it should not be generalized as the mentality and views of the Chinese in boarder sense. Besides, the use of the fact sheet largely facilitated the discussions with the informants. It, however, might have emotional influences on them and affected their position to take. The year 2019 is a critical period to Hong Kong. The large scale social movements and the outbreak of new coronavirus have severe impacts on the catering industry, which might have an impact on the responses of the informants.

\section{References}

Abrahamse, W. and Steg, L. (2013). Social Influence Approaches to encourage Resource Conservation: a meta analysis, Global Environmental Change, 23, 1773-1785

Dai, Y.C., Lin, Z.Y., Xu, D.Y., Huang, W.F. and Harder, M.K. (2016). Information strategy failure: personal interaction success, in urban residential food waste segregation, Journal of Cleaner Production, 134(A), 298 309.

De Young, R. (1993). Changing behaviour and making it stick: the conceptualization and management of conservation behaviour, Environmental Behaviours, 25, 485-505

Devenyns, J. (2019). From trash to treasure: Upcycled food waste is worth \$46.7B, FoodDIVE, available on: https://www.fooddive.com/news/from-trash-to-treasure-upcycled-food-waste-is-worth-467b/555326/

Gustavsson, J. Cederberg, C. and Sonesson, U. (2011). Global Food Losses and Food Waste, Save Food Congress, Dusseldorf, Gernmany

Gonzales, M.H., Aronson, E. and Costanzo, M.A. (1988). Using social cognition and persuasion to promote energyconservation - a quasi-experiment, Journal of Applied Social Psychology, 18, 1049-1066

Lundqvist, J., Fraiture, C. and Molden, D. (2008). Saving Water: From Field to Fork - Curbing Losses and Wastage in the Food Chain. SIWI Policy Brief. SIWI.

Papargyropoulou, E., Lozano, R. Stinberger, J.K., Wright, N. and Ujang, Z. (2014). The food waste hierarchy as a framework for the management of food surplus and food waste, Journal of Clearner Production, 76, 106 - 115.

Tukker, A., Cohen, M.J., Hubacek, K. and Mont, O. (2010). The impacts of household consumption and options for change, Journal of Industrial Ecology, 14 (1), 13-30.

UNEP. (2011). Decoupling Natural Resource Use and Environmental Impacts from Economic Growth, United Nations Environment Programme, Paris

UNHSP. (2010). Solid Waste Management in the World's Cities 